\title{
PEMIKIRAN HARUN NASUTION TENTANG PENDIDIKAN DAN RELEVANSINYA DENGAN PENDIDIKAN DI ERA MODERN
}

\author{
Muchammad Iqbal Chailani \\ UIN Sunan Kalijaga Yogyakarta \\ iqbalchailani39@gmail.com
}

\begin{abstract}
Education has a important role in the advancement of human civillization, especially in terms of developing normative values so that education not only creates intelligent buman beings but also creates humans who know their responsibilities as servants of God and soxial beings. Problems often occur big that result from the destruction of buman morals that do not inspire Islamic values. Harun Nasution had the idea of Islamic renewal which is often referred to as "Gebrakan Harun Nasution" which calls for the rise of Muslims not only marked by overflowing religius emotions, but must be based on deep, comprehensive, philosophical thinking on the religion of Islamic Departingg from this, of course there relevance between Harun Nasution's perspective about education and the national education system (kurikulum) in Indonesia in modern times.
\end{abstract}

Keywords: Harun Nasution, Education, Modern Times

\section{PENDAHULUAN}

Pendidikan Islam ialah kegiatan yang dilakukan secara sadar serta terencana dengan cara menumbuhkembangkan, memperbaiki, memimpin, melatih, mengasuh peserta didik agar ia secara aktif dapat mengembangkan potensi yang ada dalam dirinya dengan tujuan memiliki kekuatan spiritual keagamaan, ilmu, akhlak mulia, dan keterampilan yang diperlukan dalam menjalani hidup di dunia dan menuju akhirat sesuai dengan nilai-nilai Islam. ${ }^{1}$

Islam mengembangkan ilmu yang bertolak dari iman, Islam dan takwa. Ilmu dan teknologi dikembangkan untuk memupuk keimanan, bukan untuk

1 Maragustam, Filsafat Pendidikan Islam (Menuju Pembentukan Karakter Menghadapi Arus Globalisasi), (Yogyakarta: Kurnia Kalam Semesta, 2012), hlm. 91.

Manazhim : Jurnal Manajemen dan Ilmu Pendidikan

Volume 1, Nomor 2, Agustus 2019; 45-60

https://ejournal.stitpn.ac.id/index.php/manazhim 
mengendalikannya. Metode berpikir juga harus ditata sinkron dan sekaligus koheren dengan keimanan kepada Allah, Rasul, Kitab Allah, malaikat, hari kiamat, dan takdir. Keimanan bukan dipupuk secara dogmatik, melainkan dipupuk secara rasional. Bukan secara positivistik (yang hanya mengakui kebenaran empirik sensual), tetapi rasional ontologik yang mengakui kebenaran sensual, logik dan etik; yang aksiologik mengakui nilai-nilai sensual, logic dan transendental; dan yang eistimologik menggunakan pembuktian kebenaran yang bukan hanya menjangkau yang sensual dan logik saja, melainkan juga menggunakan metode berpikir yang mampu menjangkau kebenaran etik dan kebenaran transendental. ${ }^{2}$

Harun berperspektif bahwa harus dilakukan adanya reformasi dalam dunia pendidikan Islam. Fenomena yang muncul saat itu banyak di antara masyarakat Indonesia yang beranggapan ajaran Islam sebagai ajaran yang sempit dan konvensional. Karena pada kenyataannya sistem pendidikan Islam pada saat itu dipusatkan pada ajaran-ajaran ibadah dan fiqih,yang secara umum di titik beratkan pada mazhab Syafi'i. Ada beberapa aspek yang sekiranya harus ditambahkan dalam materi pendidikan Islam di Indonesia khususnya di dalam perguruan tinggi Islam seperti dasar-dasar hukum Islam, perbandingan mazhab, teologi dan aliran-aliran yang terdapat didalamnya, filsafat, mistisme, sejarah dan kebudayaan Islam dari zaman klasik sampai zaman modern. Menurut Harun Nasution tidak dapat dipungkiri lagi bahwa akal memiliki kedudukan dalam wilayah agama Islam, yang penting dalam hal ini adalah menentukan dan menjelaskan batasan-batasan akal, sebab kita semua meyakini bahwa hampir semua kaum muslimin berupaya dan berusaha mengambil manfaat akal dalam pengajaran agama Islam dan penjelasan keyakinan agama secara argumentatif.

Atas dasar latar belakang masalah di atas penulis ingin memaparkan tentang perjalanan hidup Harun Nasution dalam mengembangkan kemampuan intelektualnya dari pendidikan dari keluarga hingga Ia menempuh studi di luar negeri. Selain itu penulis juga ingin memaparkan tentang pemikiran Harun Nasution mengenai pendidikan dan relevansi pemikiran Harun Nasution terhadap pendidikan di Indonesia.

2 Ahmad Janan Asifudin, Mengungkit Pilar-Pilar Pendidikan Islam (Tinjauan Filosofis), (Yogyakarta: Sunan Kalijaga Press, 2009), hlm. Xi. 
Jenis penelitian yang di pakai dalam tulisan ini adalah menggunakan kajian kepustakaan library research. Dengan menggunakan jenis penelitian ini, penulis berusaha menggali atau memahami pemikiran tokoh tertentu melalui karya-karya yang ditinggalkannya. Karya yang di maksud bisa berbentuk buku, surat pesan dan dokumen lainnya. Namun di sini penulis ingin mencari berbagai informasi tentang Harun Nasution tentang pemikiran pembaharuan Islam dan kiprahnya di dunia pendidikan melalui sumber buku. Sumber buku yang di pakai adalah berupa buku primer yang merupakan buku hasil tulisan dari tokoh yaitu Harun Nasution dan juga buku sekunder yang merupakan karya dari orang lain yang mengkaji tentang tokoh Harun Nasution.

\section{Riwayat Kehidupan Harun Nasution}

Harun Nasution adalah seorang tokoh pendidikan kenamaan di Indonesia yang lahir di Pemantang Siantar, Sumatera Utara, pada hari Selasa 23 September 1919. Ayah beliau bernama Abdul Jabar Ahmad yang merupakan seorang ulama di daerah Mandailing, Tanah Bato, Tapanuli Selatan. Dari segi ekonomi, ayahnya adalah seorang berkecukupan serta pernah menduduki jabatan sebagai qadhi, hakim agama dan imam masjid di Kabupaten Simalungun. Karena kemampuannya dalam bidang ekonomi ia berkesempatan pergi ke Mekkah untuk melaksanakan ibadah Haji pada saat masih muda. Dan Ibunya adalah seorang keturunan ulama yang berasal dari tanah Bato Mandailing, Tapanuli selatan. Pada masa gadisnya ia pernah bermukim di Makkah dan pandai berbahasa Arab. Kemudian Harun Nasution adalah anak ke empat dari lima bersaudara. Saudara pertama dari Harun Nasution bernama M Ayyub, kedua M. Khalil, ketiga Sa'idah, dan yang terakhir adalah Hafsah. Kedua orang tua Harun Nasution yang berpendidikan agama senantiasa memberikan kontribusi terhadap dalam penanaman pendidikan agamanya. ${ }^{3}$

Terlebih Harun Nasution sendiri pernah mengatakan :

"Suasana keagamaan yang ditanamkan ibuku di rumah benar-benar membekas dalam hatiku. Ibuku menetapkan disiplin keras, di rumah aku belajar mengaji sejak pukul empat hingga lima sore. Seusai shalat

${ }^{3}$ Herlina Harahap, Pembaharuan Pendidikan Islam Perspektif Harun Nasution, (Pontianak: STAIN Pontianak Press, 2016), hlm.35. 
magrib aku mengaji Alquran dengan suara keras hingga waktu Isya'. Kalau bulan puasa bertadarus di masjid hingga jam dua belas malam. Setiap pagi aku bangun subuh untuk shalat berjamaah".

Dalam dunia pendidikan, Harun Nasution telah menempuh beberapa pendidikan di Sekolah formal. Ia pertama kali sekolah dengan masuk pada Sekolah Dasar milik Belanda pada waktu itu atau yang sering disebut dengan Hollandsch-InLandshe School (HIS). Harun Nasution menyelesaikan studinya di sekolah tersebut selama tujuh tahun dan lulus pada usia 14 tahun. Selama mengikuti pendidikan di sekolah dasar Belanda tersebut, Ia berkesempatan mempelajari bahasa Belanda dan ilmu pengetahuan umum. Setelah itu pada tahun 1934 Ia meneruskan studinya ke Moderne Islamietische Kweekschool (MIK) dan tamat di sekolah tersebut pada tahun 1937. Sekolah tersebut adalah sekolah guru menengah swasta pertama modern yang ditempuh selama tiga tahun. Ia belajar di sana dengan bahasa pengantarnya adalah bahasa Belanda. ${ }^{5}$

Dalam jenjang pendidikan tinggi, Harun Nasution berkesempatan untuk menempuh pendidikan di Universitas Al Azhar Kairo Mesir Fakultas Ushuludin pada tahun 1940. Tidak hanya bersekolah di Al Azhar saja, Harun Nasution juga berkesempatan memasuki Universitas Amerika, Kairo dan memperoleh gelar Bachelor of Art (BA) dalam studi sosial pada tahun 1952. Selepas mengenyam pendidikan di Mesir, Harun Nasution kembali ke Indonesia pada tahun 1953, dan di tugaskan di Departemen Luar Negeri Bagian Timur Tengah kala itu. Selama tiga tahun sejak tahun 1955 Ia bertugas di Brussel dan banyak mewakili berbagai pertemuan, terutama karena kemampuannya bahasa Belanda, Perancis serta Inggris.

Setelah itu Harun Nasution melanjutkan perjalanan studinya ke Mesir tepatnya di Al Dirasah Al Islamiyyah namun terhambat biaya, maka studinya tidak dapat dilanjutkan. Akhirnya Ia menerima beasiswa dari Institute Of Islamic Studies McGill di Montreal Kanada sehingga pada tahun 1962 ia melanjutkan studinya di Universitas tersebut. Kemudian pada tahun 1965 Harun Nasution berhasil memperoleh gelar Magister of Art (MA) dalam Studi Islam dengan judul tesisnya The

${ }^{4}$ Ibid., hlm.36.

${ }^{5}$ Muhammad Husnol Hidayat, Harun Nasution Dan Pembaharuan Pendidikan Islam, dalam Jurnal Tadris, Vol. 10, No.1, (2015), hlm. 25. 
Islamic State in Indonesia: The Rise of The Ideology, The Movement for Its Creation and The Theory of The Masjumi. Tiga tahun kemudian tepatnya pada tahun 1968 , Harun Nasution mendapatkan gelar Doktor (Ph.D) dalam Studi Islam di McGill Kanada, dengan disertasi yang berjudul : The Place of Reason in Abduh's Theology. Its Impact on His Theological System and Views.

Setelah mendapatkan gelar Doktor, pada tahun 1969 Harun Nasution kembali ke Indonesia dan melanjutkan karirnya sebagai profesional tenaga pendidikan di IAIN Jakarta. Di samping itu beliau juga menjabat sebagai tenaga pendidik (dosen luar biasa) di IKIP Jakarta pada tahun 1970, Dosen di Universitas Nasional Jakarta tahun 1970, dan Fakultas dosen Sastra di Universitas Indonesia Jakarta (UNJ) pada tahun 1975. Tidak hanya itu karir beliau juga merambah pada jajaran jabatan tinggi dii kampus, beliau menjadi rekor di IAIN Syarif Hidayatullah Jakarta selama 11 tahun (1973-1984), selain itu beliau menjabat sebagai ketua lembaga pembinaan pendidikan agama di IKIP Jakarta dan terakhir menjadi dosen Fakultas Pascasarjana IAIN Syarif Hidayatullah Jakarta sejak 1982 hingga akhir hayatnya pada tahun $1998 .^{7}$

Gagasan utama dari Harun Nasution adalah tentang mengubah pola pikir masyarakat luas tentang Islam, maka beliau menjadi orang pertama lulusan timur tengah yang banyak sekali membawa pembaharuan. Harun Nasution adalah contoh alim, yakni seorang yang mempunyai perspektif bahwa ilmu pengetahuan tidak memiliki batas dan yang ada adalah perbatasan. Karena dalam mencari ilmu banyak jalan, jadi artinya sumber kebahagiaan tertinggi itu ialah orang yang senantiasa mencari, selalu bertanya, selalu ingin tahu apa sebenarnya yang sedang terjadi, mereka yang tidak pernah berhenti. Oleh karena itu agama adalah dianggapnya sebagai jalan. Karena menyadari hal ini, Harun Nasution terus berjalan dan terus mencari. ${ }^{8}$

${ }^{6}$ Herlina Harahap, Pembaharuan Pendidikan Islam Perspektif Harun Nasution..., hlm. 37.

${ }^{7}$ Harun Nasution, Islam Rasional, (Jakarta: Mizan, 1995), hlm. 5.

8 Efrianto Hutasuhut, Akal dan Wahyu Dalam Islam Perbandingan Pemikiran Harun Nasution dan Muhamad Abduh, dalam Jurnal Al lubb, Vol. 2, No. 1, (2017), hlm.189. 


\section{Perkembangan Pemikiran dan Karya-Karyanya}

Pembaharuan Islam dalam arti yang seluas-luasnya adalah merupakan ciri khas dari pemikiran Harun Nasution. Pemberharuan yang tidak terbatas dalam bidang pemikiran saja seperti teologi, filsafat, mistisisme dan hukum, dan juga meliputi seluruh segi kehidupan kaum muslimin. Corak pemikiran Harun Nasution sangat terlihat seperti mengadopsi tradisi intelektual dan akademis kosmopolitan (Barat), tetapi hampir sepenuhnya mewarisi dasar-dasar pemikiran Islam abad pertengahan. Beliau sangat menguasai pemikiran para filosuf Islam dan termasuk pakar dalam dunia tasawuf membuatnya dapat merumuskan konsep yang akurat tentang pemikirannya guna membangun masyarakat muslim Indonesia, Beliau selalu menyebutkan bahwa kebangkitan umat Islam tidak hanya dijewantahkan melalui emosi keagamaan yang meluap-luap, tetapi harus didasarkan pemikiran yang mendalam filosofis dan menyeluruh terhadap ajaran agama Islam tersebut. ${ }^{9}$

Untuk mewujudkan hal tersebut Harun Nasution memiliki langkah yang tepat yang sering disebut dengan "Gebrakan Harun". Ada tiga langkah yang dimaksud yaitu :

1. Meletakkan pemahaman yang mendasar dan menyeluruh terhadap Islam. Menurutnya dalam Islam terdapat dari dua ajaran pokok yatiu

a. Ajaran yang bersifat absolut dan mutlak benar, universal kekal, tidak berubah dan tidak diubah. Yang dimaksud dengan kelompok ini adalah ajaran yang terdapat dalam Qur'an dan Hadits mutawatir.

b. Ajaran yang bersifat absolut, namun relatif, tidak universal, tidak kekal dan boleh diubah. Yang berada dalam kelompok ini adalah ajaran yang dihasilkan oleh para ulama.

2. Langkah pertama yang beliau lakukan ketika diberikan mandat sebagai rektor IAIN Jakarta pada tahun 1973 adalah merevisi kurikulum IAIN di seluruh Indonesia. Hal yang paling terlihat adalah ketika mata kuliah pengantar ilmu agama, filsafat, teologi dan metode riset di masukkan dalam kurikulum IAIN guna mengubah pandangan mahasiswa tentang Islam.

9 Sugeng Solehudin, Reinventing Pendidikan Islam Harun Nsution, dalam Forum Tarbiyah, Vol. 8, No. 01, (Juni 2010), hlm. 124. 
3. Di tahun 1982, bersama dengan menteri Agama kala itu berusaha untuk membentuk fakultas pascasarjana karena kala itu belum ada organisasi sosial yang berprestasi melakukan pimpinan umat Islam masa depan. ${ }^{10}$

Adapun beberapa karya intelektual yang telah di tulis oleh Harun Nasution dalam beberapa buku adalah sebagai berikut :

1. Teologi Islam aliran-aliran sejarah analisis perbandingan (1972)

2. Falsafat Agama (1973)

3. Falsafat dan Mistisisme dalam Islam (1973)

4. Islam ditinjau Dari Beberapa Aspek (1974)

5. Teologi Islam (1977)

6. Pembaruan Dalam Islam (1975)

7. Muhammad Abduh dan Teologi Rasional Mu’tazilah (1978)

8. Akal dan Wahyu dalam Islam (1982)

9. Islam Rasional (1995). ${ }^{11}$

\section{Pemikiran Harun Nasution Tentang Pendidikan}

\section{Hakikat Pembaharuan Pendidikan Islam Harun Nasution}

Menurut Harun Nasution, istilah pembaharuan tidak lepas dengan kata modernisasi. Dalam bahasa Indonesia, kata modern, modernisasi, dan modernisme seperti yang terdapat dalam istilah "aliran-aliran modern dalam Islam" dan "Islam modernisasi". Modernisme dalam masyarakat Barat berarti aliran, gerakan dan pemahaman guna mengubah paham-paham adat-istiadat, institusi-institusi lama untuk diselaraskan atau disesuaikan dengan suasana yang baru. Di dunia barat pemahaman modernisme ajaran agama bertujuan untuk menyesuaikan ajaran-ajaran yang terdapat dalam agama Katolik dan Protestan dengan ilmu pengetahuan dan Falsafah Modern, hal tersebut menyebabkan adanya Aliran Sekularisme di dunia Barat. ${ }^{12}$

${ }^{10}$ Ibid., hlm. 125.

${ }^{11}$ Nurisman, Pemikiran Filsafat Islam Harun Nasution: Pengembangan Pemikiran Islam di Indonesia, (Yogyakarta: Teras, 2012), hlm. 87.

12 Herlina Harahap, Pembeharuan Pendidikan Islam Perspektif Harun Nasution,..., hlm. 23. 
Dalam pembaharuan Islam yang di gagas oleh Harun Nasution adalah upaya menyelaraskan antara pembaharuan pandangan ber Islam dengan kemajuan ilmu pengetahuan dan teknologi di dunia modern. ${ }^{13}$ Maksudnya adalah pembaharuan pandangan dalam Islam bukan berarti mengurangi, menambah atau teks dalam Alquran maupun teks dalam hadits, akan tetapi Harun Nasution berupaya mengubah atau menyesuaikan pemahaman atas dua teks tersebut sesuai dengan keadaan perkembangan zaman.

Pada hakikatnya pembaharuan pendidikan Islam merupakan usaha reinterpretasi berkelanjutan dan secara eksplisit di tujukan terhadap mengembangkan fitrah keberagamaan (religiusity) peserta didik (mahasiswa) agar supaya lebih mampu dalam memahami, menghayati dan mengamalkan ajaran agama Islam sesuai dengan semangat kemajuan zaman. Implikasi dari pengertian ini adalah pendidikan Agama Islam merupakan komponen yang tidak terpisahkan dalam kehidupan sehari-hari. Bahkan tidak berlebihan bila dikatakan bahwa semangat pembaharuan memosisikan pendidikan Islam sebagai jalur pengintegrasian wawasan agama dengan bidang-bidang studi (pendidikan) yang lain. Implikasi lebih lanjut mengenai pemberharuan Islam adalah, pendidikan agama harus dilaksanakan sejak usia dini melalui pendidikan keluarga sebelum anak memperoleh pendidikan dan pengajaran ilmu-ilmu yang lain. ${ }^{14}$ Dari pengertian di atas dapat ditarik kesimpulan bahwa semangat dari pembaharuan Islam adalah untuk membentuk terwujudnya insan kamil yang berlandaskan Alquran dan Sunnah.

Dengan demikian diharapkan seseorang yang telah paham akan gebrakan Harun Nasution tersebut bisa memiliki pemahaman bahwa segala sesuatu yang terjadi di dunia ini tidak hanya serta merta langsung dari Allah, tanpa bisa di rasio dengan akal manusia. Artinya segala fenomena yang terjadi di alam semesta ini pasti ada hukum kausalitasnya. Memang segala sesuatu akan terjadi karena takdir Allah namun ada sebab akibat (kausalitas) yang bisa dinalar oleh pikiran manusia dengan berlandaskan sumber-sumber Islam baik

${ }^{13}$ Muhammad Husnol Hidayat, Harun Nasution Dan Pembaharuan Pendidikan Islam..., hlm. 28. ${ }^{14}$ Ibid., hlm. 29. 
Alquran dan Assunah. Misalnya dalam Alquran Qs Azzumar 39;21 diterangkan bahwa Allah menurunkan hujan dari langit ke muka bumi ini adalah sebagai sumber-sumber kehidupan bagi makhluk hidup.

Ditinjau dari hal tersebut dengan pemikiran Islam Rasional yang di gagas oleh Harun Nasution mengantarkan pemikiran bahwa memang benar Allah lah yang menciptakan adanya hujan namun lebih dari itu proses terjadinya hujan dari langit dan turun ke bumi bisa di kaji lebih lanjut dengan rasio manusia. Artinya terjadinya hujan di muka bumi ini ada sebab akibat (hukum kausalitas) yang mempengaruhinya. Terjadinya hujan disebabkan oleh proses kondensasi di awan yang mengubah awan menjadi molekul air, terjadinya awan disebabkan oleh adanya proses evaporasi air laut yang kemudian mengubah air menjadi awan dan seterusnya hingga menjadi lah siklus hujan. Dari sedikit gambaran tentang siklus hujan itu menunjukkan bahwa segala sesuatu yang terjadi di alam semesta ini pasti ada hukum kausalitasnya atau hukum sebab akibat.

Harun Nasution juga melakukan sebuah gebrakan dalam pengembangan sistem pendidikan di bidang akademik khususnya pendidikan perguruan tinggi. Dalam tradisi akademik perguruan tinggi Islam di Indonesia, ada tiga perubahan dan pembaharuan sistem yang diupayakannya yaitu sebagai berikut :

a. Memasukan strategi pembelajaran yang mengasah kemampuan pemikiran mahasiswa tentang Islam seperti diskusi dan seminar. Karena sebelumnya sistem pembelajaran di perkuliahan dinilai feodal.

b. Harun Nasution menuntut mahasiswanya untuk menulis. Hal tersebut ditujukan untuk melatih kemampuan mahasiswa untuk menuangkan ide dan gagasannya tidak hanya di lontarkan lewat lisan namun ditulis dengan kaidah penulisan yang sistematis.

c. Mahasiswa dituntut untuk memahami Islam secara universal. Dominasi pendekatan fiqih selama ini dalam sistem pengkajian Islam membuat kajian Islam agak mandek. ${ }^{15}$

15 Muhammad Husnol Hidayat, Harun Nasution Dan Pembaharuan Pendidikan Islam.., hlm. 32. 


\section{Ruang Lingkup Pendidikan Menurut Harun Nasution}

a. Hubungan Antara Agama dan Moral

Hubungan agama dengan moral sangat erat sekali dan merupakan hal yang esensial. Demikian juga halnya dengan Islam. Di dalam Al-Qu'an banyak terdapat ajaran-ajaran mengenai akhlak. Dan Nabi Muhammad sendiri menjelaskan bahwa beliau diutus ke dunia ini untuk menyempurnakan ajaran-ajaran mengenai budi luhur. ${ }^{16}$

Dalam Pendidikan agama terutama di TK, SD, SMP, SMA, pendidikan moral inilah rasanya yang perlu diutamakan. Pelajaranpelajaran mengenai keagamaan lain, terutama ibadah sebaiknya dihubungkan dengan pendidikan moral ini. Di Perguruan tinggi, pendidikan moral masih dapat dilanjutkan, tetapi di sini yang perlu ditekankan adalah pendidikan spiritual dan pelajaran rasional tentang ajaran agama. ${ }^{17}$

b. Kurikulum

Penyusunan kurikulum atau silabus pendidikan agama di sekolahsekolah umum sebaiknya didasarkan pada hal-hal berikut:

Untuk TK dan tahun-tahun pertama SD mencakup: (1) mengenal Tuhan sebagai pemberi dan sumber dari segala yang dikasihi dan disayangi anak didik (2) berterima kasih atas pemberian-pemberian itu, (3) pendidikan: jangan menyakiti orang lain, binatang dan tumbuhtumbuhan, (4) pendidikan berbuat baik dan suka menolong orang lain, binatang dan tumbuh-tumbuhan, (5) pendidikan sopan santun dalam pergaulan.

Untuk SMP dan selanjutnya meliputi: (1) kenal dan cinta kepada Tuhan sebagai yang maha Pengasih, Penyayang dan Pengampun, (2) Ibadah sebagai tanda terima kasih kepada Tuhan atas nikmat-Nya, (3) memperdalam rasa sosial dan kesediaan menolong orang lain, binatang dan lain-lain, (4) ajaran dan didikan tentang akhlak Islam, (5) pengetahuan

\footnotetext{
${ }^{16}$ Herlina Harahap, Pembeharuan Pendidikan Islam Perspektif Harun Nasution, ..., hlm. 109.

17 Ibid., hlm. 110.
} 
tentang agama islam seperti tauhid, figh, dan lain-lain, sekadar perlu dan sesuai dengan perkembangan anak didik. ${ }^{18}$

Untuk SMP dan SMA mencakup: (1) memperdalam hal-hal tersebut dalam sub SD di atas, (2) ibadah di sini diajarkan sebagai latihan spiritual sebagai pendekatan terhadap Tuhan Tujuannya ialah memperoleh kesucian dan ketentraman jiwa, (3) pengetahuan tentang agama diperdalam dan diperluas, (4) menanamkan rasa toleransi terhadap mazhab-mazhab yang ada di dalam agama, (5) dedikasi terhadap masyarakat.

Untuk Tingkat PT mencakup: (1) memperdalam rasa keagamaan dengan pendekatan spiritual dan intelektual, (2) Ibadah sebagai didikan mahasiswa untuk merendahkan hati, di samping berpengetahuan tinggi, tidak merasa takabur tapi sadar bahwa di atasnya masih terdapat Zat yang Maha Mengetahui dan berkuasa dari manusia manapun, (3) memperluas pengetahuan agama secara global, (4) memperdalam rasa toleransi, (5) memperdalam rasa dedikasi terhadap masyarakat. ${ }^{19}$

c. Metode

Karena tujuan utama dari pendidikan Islam adalah pendidikan moral, maka metode yang sebaiknya dipakai ialah: (1) Pemberian contoh dan teladan, (2) Nasihat, (3) tuntunan dalam menyelesaikan persoalan, (4) kerjasama dengan lingkungan, (5) kerjasama dengan pendidik lainnya, (6) Tanya jawab dalam hal intelektual. ${ }^{20}$

d. Kualitas Pendidik Agama

Menurut Harun Nasution ada beberapa syarat-syarat yang perlu bagi pendidik agama antar lain: (1) menjadi teladan, (2) menguasai ilmu pengetahuan, (3) mempunyai pengetahuan yang luas tentang agama selalin pengetahuan yang menjadi jurusan, (4) mempunyai pengetahuan yang seimbang dengan pengetahuan siswa. ${ }^{21}$

\footnotetext{
${ }^{18}$ Ibid., hlm. 111.

${ }^{19}$ Ibid., hlm. 112.

${ }^{20}$ Ibid., hlm. 113.

${ }^{21}$ Ibid., hlm. 114.
} 


\section{Ciri-ciri Dunia Modern}

Pendidikan pada umumnya dan pendidikan Islam khususnya mempunyai peranan yang sama bagi kehidupan umat manusia agar manusia dapat mengarungi kehidupan di dunia dan memperoleh kemenangan-kemenangan yang hakiki, yaitu memperoleh kebahagiaan dan kenikmatan hidup tidak hanya di dunia yang fana ini tetapi juga pada kehidupan akhirat yang kekal. ${ }^{22}$

Hidup di dunia tampaknya telah sampai pada era global/ modern yaitu era di mana kehidupan telah mendunia ditandai dengan, transportasi ke segala arah dengan begitu mudah, komunikasi dengan cepat, dan perdagangan bebas pasti terjadi. Hal itu berdampak pada perubahan dalam bermasyarakat, berekonomi, dan berpolitik pada setiap negara, sehingga menimbulkan berbagai permasalahan menyangkut pada pendidikan umumnya dan pendidikan Islam pada khususnya. ${ }^{23}$

Menurut Daniel Bell, sebagaimana dikutip oleh Mochtar Buchori, bahwa di era global saat ini masyarakat di hadapkan kepada lima kecenderungan yang membawa dampak bagi kehidupan yang amat luas, kelima kecenderungan tersebut sebagai berikut:

1. Kecenderungan untuk berintegrasi dalam kehidupan ekonomi, yang mana akan berimplikasi pada dunia pendidikan.

2. Kecenderungan untuk berpecah belah (fragmatasi) dalam kehidupan politik. Fragmatasi ini terjadi karena semakin terbukanya kebebasan untuk menyatakan hak-hak seseorang, menuntut perlakuan yang lebih adil dan demokratis, peningkatan dan pemerataan kesejahteraan, baik dalam bidang ekonomi, kesehatan, pendidikan, dan sebagainya.

3. Kecenderungan interdependesi (kesalingtergantungan) antara satu negara dengan negara lain.

4. Meningkatnya kemajuan di bidang ilmu pengetahuan dan teknologi yang selanjutnya mengubah secara radikal situasi pasar kerja.

5. Kecenderungan semakin tergesernya kebudayaan dan tradisi masa lalu oleh kebudayaan dan tradisi baru yang selanjutnya menimbulkan apa yang

22 Amin Abdullah. Dkk, Pendidikan Islam dan Tantangan Globalisasi Buab Pikiran Seputar: Filsafat, Politik, Ekonomi, Sosial, dan Budaya, (Yogyakarta: Ar-Ruzz Media, 2004), hlm. 25-26.

23 Ibid., hlm. 26. 
kita sebut dengan new colonization in culture (penjajahan baru dalam bidang kebudayaan). Yaitu perubahan pola pikir, sikap, perilaku dalam berpakaian, dll. ${ }^{24}$

\section{Relevansi Pemikiran Pembaharuan Pendidikan Islam Harun Nasution dengan Pendidikan di Era Modern}

Dalam pembahasan ini, penulis akan mencoba mengkaji tentang beberapa relevansi antara pemikiran atau gagasan Harun Nasution dengan pendidikan di dunia modern khususnya di Indonesia.

1. Dasar Pendidikan

Harun Nasution adalah seorang tokoh intelektual muslim yang dikenal dengan pembaharuan Islamnya. Pembaharuan yang dimaksud adalah tidak terbatas dalam bidang pemikiran saja seperti teologi, filsafat, mistisisme dan hukum, tetapi juga meliputi seluruh segi kehidupan kaum muslimin. Artinya hakikatnya pembaharuan pendidikan Islam merupakan usaha reinterpretasi berkelanjutan dan lebih khusus ditekankan untuk mengembangkan fitrah keberagamaan (religiusity) subjek didik agar lebih mampu memahami, menghayati dan mengamalkan ajaran agama Islam sesuai dengan semangat zaman

Pemikiran tentang pembaharuan pendidikan Islam tersebut terdapat dengan Undang-Undang Nomor 20 Tahun 2003 sistem pendidikan nasional pada BAB II Pasal 3 tentang dasar, fungsi dan tujuan pendidikan nasional yang berbunyi :

"Pendidikan nasional berfungsi mengembangkan kemampuan dan membentuk watak serta peradaban bangsa yang bermartabat dalam rangka mencerdaskan kehidupan bangsa, bertujuan untuk berkembangnya potensi peserta didik agar menjadi manusia yang beriman dan bertakwa kepada tuhan yang maha esa, berakhlak mulia, sehat, berilmu, cakap, kreatif, mandiri dan menjadi warga negara yang demokratis serta bertanggung jawab". ${ }^{25}$

${ }^{24}$ Abuddin Nata, Manajemen Pendidikan, Mengatasi kelemahan Pendidikan Islam di Indonesia, Jakarta: Prenada Media, 2003), hlm. 69.

25 Salinan Undang-Undang Sisdiknas Nomor 20Tahun 2003, hlm.3. 
2. Prinsip Penyelenggaraan Pendidikan

Untuk mencapai tujuan pendidikan tentunya diperlukan prinsip penyelenggaraan pendidikan yang baik. Harun Nasution memiliki gagasan dalam penyelenggaraan pendidikan yang baik. Karena tujuan utama dari pendidikan Islam adalah pendidikan moral, maka metode yang sebaiknya dipakai ialah: (1) Pemberian contoh dan teladan, (2) Nasihat, (3) tuntunan dalam menyelesaikan persoalan, (4) kerjasama dengan lingkungan, (5) kerjasama dengan pendidik lainnya, (6) Tanya jawab dalam hal intelektual

Pemikiran tentang prinsip penyelenggaraan pendidikan tersebut berkautan dengan Undang-Undang Nomor 20 Tahun 2003 sistem pendidikan nasional pada BAB III Pasal 4 tentang prinsip penyelenggaraan pendidikan nasional pada poin 1,4 dan 5 yang berbunyi :

a. Pendidikan diselenggarakan secara demokratis dan berkeadilan serta tidak diskriminatif dengan menjunjung tinggi hak asasi manusia, nilai keagamaan, nilai kultural, dan kemajemukan bangsa.

b. Pendidikan diselenggarakan dengan memberi keteladanan, membangun kemauan, dan mengembangkan kreativitas peserta didik dalam proses pembelajaran.

c. Pendidikan diselenggarakan dengan mengembangkan budaya membaca, menulis, dan berhitung bagi segenap warga masyarakat. ${ }^{26}$

3. Sistem Pendidikan

Harun Nasution melakukan sebuah gebrakan baru ketika beliau diangkat menjadi Rektor IAIN Syarif Hidayatullah Jakarta pada tahun 1973, langkah pertama yang dilakukannya adalah merombak kurikulum IAIN seluruh Indonesia, Pengantar Ilmu Agama, Filsafat, Teologi dan metode riset dimasukkan dengan harapan akan mengubah pandangan mahasiswa. Harapan Harun Nasution tersebut tertuang dalam Bab X Kurikulum pasal 36 ayat 3 yang berbunyi:

Kurikulum disusun sesuai dengan jenjang pendidikan dalam kerangka negara kesatuan republik Indonesia dengan memperhatikan:

${ }^{26}$ Ibid., hlm. 4. 

a. Peningkatan iman dan takwa
b. Peningkatan akhlak mulia
c. Peningkatan potensi, kecerdasan, dan minat peserta didik
d. Keragaman potensi daerah dan lingkungan
e. Tuntutan pembangunan daerah dan nasional
f. Tuntutan dunia kerja
g. Perkembangan ilmu pengetahuan, teknologi dan seni
h. Agama
i. Dinamika perkembangan global
j. Persatuan nilai-nilai nasional dan kebangsaan ${ }^{27}$

4. Pendidik dan Tenaga Kependidikan

Menurut Harun Nasution ada beberapa syarat-syarat yang perlu bagi pendidik agama antar lain: (1) menjadi teladan, (2) menguasai ilmu pengetahuan, (3) mempunyai pengetahuan yang luas tentang agama selain pengetahuan yang menjadi jurusan, (4) mempunyai pengetahuan yang seimbang dengan pengetahuan siswa

Gagasan Harun Nasution tentang kualifikasi tenaga pendidik tersebut berkaitan dengan Undang-Undang Nomor 20 Tahun 2003 sistem pendidikan nasional pada BAB XI Pasal 40 tentang kewajiban pendidik dan tenaga kependidikan yang berbunyi :

a. Menciptakan suasana pendidikan yang bermakna, menyenangkan, kreatif, dinamis, dan dialogis;

b. Mempunyai komitmen secara profesional untuk meningkatkan mutu pendidikan; dan

c. Memberi teladan dan menjaga nama baik lembaga, profesi, dan kedudukan sesuai dengan kepercayaan yang diberikan kepadanya. $^{28}$ 


\section{KESIMPULAN}

Pembaharuan Islam yang di gagas oleh Harun Nasution adalah kemajuan dalam bidang ilmu pengetahuan dan teknologi bukanlah sesuatu yang tabu yang harus dipisahkan oleh ajaran Islam. justru Harun Nasution mempunyai gagasan "Gebrakan Harun" yang berupaya mengubah paradigma masyarakat Islam di Indonesia yang seakan terkesan memisahkan antara pemahaman agama dengan kemajuan ilmu pengetahuan ke arah pembaharuan Islam.

Dalam prinsip penyusunan kurikulum dalam sebuah lembaga pendidikan menurut Harun Nasution harus ada kesesuaian materi dengan jenjang pendidikannya. Selain itu dalam rangka pencapaian pendidikan yang sesuai dengan tujuan pendidikan harus ada komponen-komponen yang harus diperbaiki seperti metode pendidikan, tenaga pendidik, dan bahan ajar yang akan diajarkan kepada peserta didik.

\section{DAFTAR PUSTAKA}

Asifudin, Ahmad Janan, Mengungkit Pilar-Pilar Pendidikan Islam (Tinjauan Filosofis), Yogyakarta: Sunan Kalijaga Press, 2009.

Harahap, Herlina, Pembaharuan Pendidikan Islam Perspektif Harun Nasution, Pontianak: STAIN Pontianak Press, 2016.

Husnol Hidayat, Muhammad, Harun Nasution Dan Pembaharuan Pendidikan Islam, dalam Jurnal Tadris, Vol. 10 No. 1, 2015.

Hutasuhut, Efrianto, Akal dan Wahyu Dalam Islam Perbandingan Pemikiran Harun Nasution dan Muhamad Abduh, dalam Jurnal Al lubb, Vol. 2, No. 1, 2017.

Maragustam, Filsafat Pendidikan Islam (Menuju Pembentukan Karakter Menghadapi Arus Globalisasi), Yogyakarta: Kurnia Kalam Semesta, 2012.

Nasution, Harun, Islam Rasional, Jakarta : Mizan, 1955.

Nata, Abuddin, Manajemen Pendidikan, Mengatasi kelemahan Pendidikan Islam di Indonesia, Jakarta: Prenada Media, 2003.

Nurisman, Pemikiran Filsafat Islam Harun Nasution: Pengembangan Pemikiran Islam di Indonesia, Yogyakarta: Teras, 2012.

Salinan Undang-Undang Sisdiknas Nomor 20 Tahun 2003.

Solehudin, Sugeng, Reinventing Pendidikan Islam Harun Nsution, dalam Forum Tarbiyah, Vol. 8, No. 1, 2010. 